\title{
Introduction to GPS geodetic infrastructure for land subsidence monitoring in Houston, Texas, USA
}

\author{
G. Wang, J. Welch, T. J. Kearns, L. Yang, and J. Serna Jr. \\ Department of Earth and Atmospheric Sciences, University of Houston, Houston, Texas, 77204, USA \\ Correspondence to: G. Wang (gwang@uh.edu) \\ Published: 12 November 2015
}

\begin{abstract}
Houston, Texas is one of the places that first employed high-accuracy GPS technology for land subsidence monitoring beginning in the late 1980s. Currently, there are over 170 permanent GPS stations located in the Houston metropolitan area. This article summarizes the current GPS geodetic infrastructure in the Houston metropolitan area, which is comprised of three components: a dense GPS network with 170 permanent stations, a stable Houston reference frame (SHRF14), and sophisticated software packages for post positioning processing. Average land subsidence and groundwater-level altitude changes during the past 10 years (2005-2014) also are presented in this paper.
\end{abstract}

\section{Introduction}

Land subsidence in the Houston, Texas area has been occurring for almost a century. Accumulated subsidence of over $3 \mathrm{~m}$ during the past century has been observed in a large area of southeast Harris County, including Houston downtown, the cities of Pasadena, Baytown, Texas City, and Galveston (Kasmarek et al., 2009). The Houston area is also suffering from faulting problems. More than 150 historically active faults have been identified in the Houston area (Shah and Lanning-Rush, 2005). Ground deformations associated with subsidence and faulting cause moderate to severe damage to hundreds of residential, commercial, and industrial structures in the Houston area each year. As a result, the foundation repair industry has been thriving in this area since the 1990s. Subsidence is of particular concern in low-lying downtown, the Houston ship channel, and the Galveston coastal areas because of the increased risk of flooding from storm surges (Coplin and Galloway, 1999). To prevent land subsidence, the Texas Legislature created the Harris-Galveston Subsidence District (HGSD) in 1975, the Fort Bend Subsidence District (FBSD) in 1989, the Lone Star Groundwater Conservation District (LSGCD) in 2001, and the Brazoria County Groundwater Conservation District (BCGCD) in 2003. One of the primary obligations of these districts is to regulate and reduce groundwater withdrawal for the purpose of minimiz- ing ground subsidence, which contributes to infrastructure damage and flooding.

In the early 1990s, the HGSD established a surveying network of 20 permanent GPS monuments for the purpose of subsidence monitoring. These GPS sites are also called Port-A-Measure (PAM) stations (Zilkoski et al., 2003). The PAM network has been continuously expanded and the number of total stations has reached 80 as of 2014. On average, HGSD continuously collected GPS data at each PAM site for one week every month prior to 2005. It now collects data for one week every other month on average. In addition to the PAM GPS network, there are over 40 Continuously Operating Reference Stations (CORS) in the Houston area (Wang and Soler, 2013). These CORS are operated by a joint effort of the National Geodetic Survey (NGS) at the National Oceanic and Atmospheric Administration (NOAA), the Texas Department of Transportation, the City of Houston, and other local agencies. Recently, the University of Houston established a real-time GPS network (HoustonNET) with 50 permanent real-time stations. The primary purpose of the HoustonNET is to provide a platform for studying multiple urban natural hazards, including subsidence, faulting, salt dome uplift, flooding, and to improve hurricane intensity forecasts in the Gulf Coast region. As of 2014, there are approximately 170 permanent GPS stations in the Houston metropolitan area (Fig. 1). Raw GPS data (RINEX files) from 


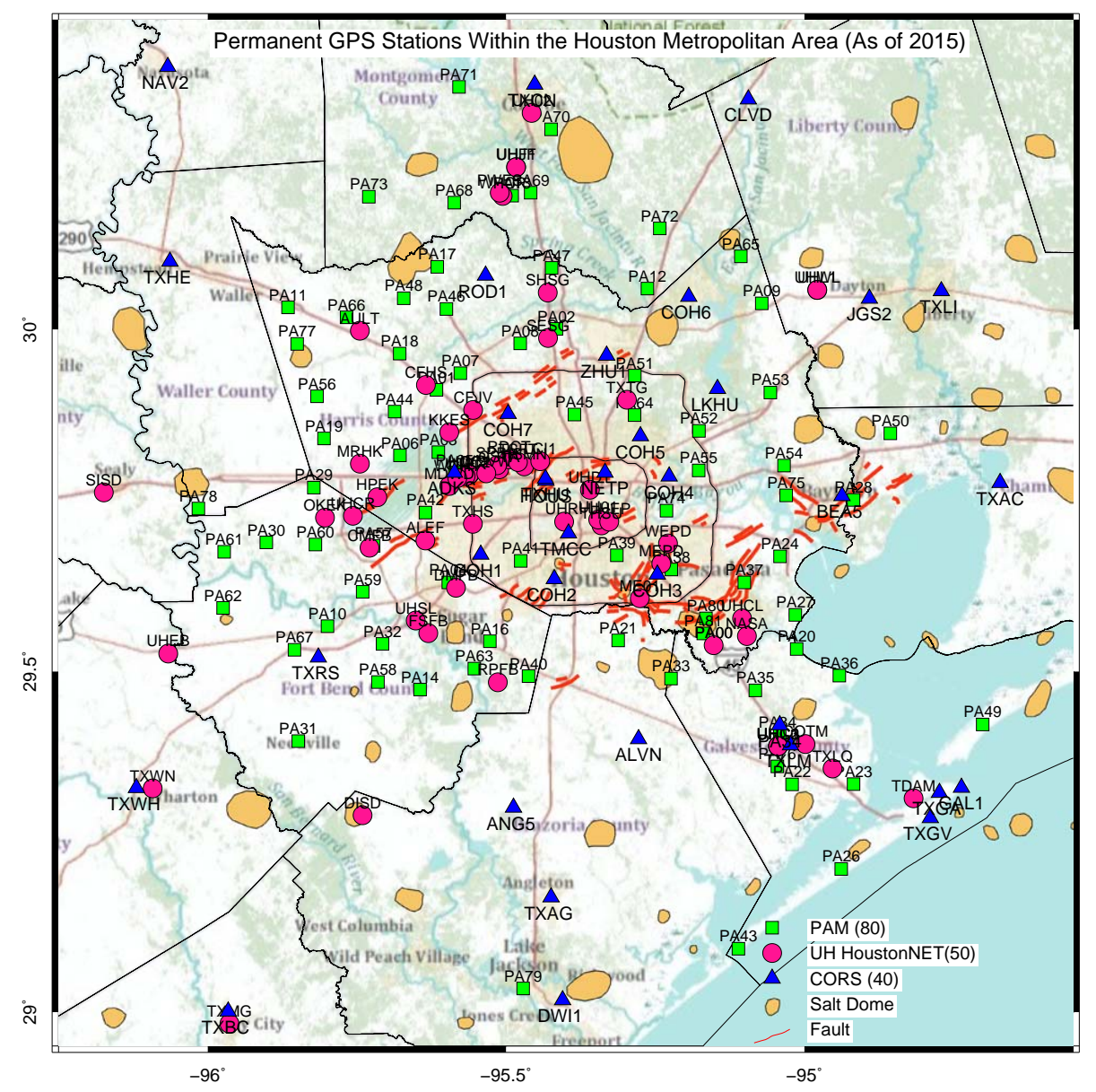

Figure 1. Map showing the locations of current permanent GPS stations within the Houston metropolitan area. The locations of salt domes and fault lines are sourced from American Association of Petroleum Geologists (2011) and from USGS (Shah and Lanning-Rush, 2005), respectively.

these stations are available to the public through HGSD and data archiving facilities at UNAVCO (https://www.unavco. org/data) and NGS (http://geodesy.noaa.gov/CORS).

\section{Stable Houston Reference Frame of 2014 (SHRF14)}

Surveying-level GPS units record satellite signals and do not directly provide high-precision positions. Additional information, such as precise satellite orbits and clock information, the modeling of atmospheric condition (dry and wet temperature and pressure) and a suitable mapping function, and complex calculations are required for obtaining precise positions. Several sophisticated GPS data post-processing software packages are available to the research community. Some such packages include GAMIT/GLOBK, GIPSY/OASIS, and Bernese. This study applied the precise point positioning (PPP) method employed by the GIPSY/OASIS (V6.3) software package (Bertiger et al., 2010) for calculating daily positions. The precision of PPP solutions has dramatically increased over the last decade. This is primarily attributed to highly precise satellite orbit and clock data provided by the International Global Navigation Satellite System (GNSS) Service (IGS, http://www.igs.org), and new algorithms used to resolve phase ambiguity with a single receiver. The PPP method has attracted broad interests in ground deformation monitoring because of its operational simplicity and high accuracy (e.g., Wang 2013; Wang et al., 2014; Wang and Soler, 2014; Yu et al., 2014). Our recent GPS study indicated that the repeatability (RMS) of the daily ambiguityresolved PPP solutions achieved $2-3 \mathrm{~mm}$ in the horizontal components and $6-8 \mathrm{~mm}$ in the vertical component within the Houston metropolitan area (Wang et al., 2013).

A complex part of GPS is that it initially provides position coordinates within a global reference frame, such as the International GNSS Service reference frame of 2008 (IGS08). In general, a global reference frame is realized with an approach of minimizing the overall movements of a large number of selected frame stations distributed worldwide. As a result, the majority of sites keep moving within a global refer- 
ence frame. Several continental-scale reference frames fixed on the North American plate have been developed by the geodetic community, such as the North American Datum of 1983 (NAD83) (Snay and Soler, 2000; Soler and Snay, 2004; Pearson and Snay, 2013), the Stable North American Reference Frame (SNARF) (Blewitt, 2008), and the North American Reference Frame of 2012 (NA12) (Blewitt et al., 2013). The average horizontal velocities in the Houston metropolitan area are approximately $15 \mathrm{~mm}$ year $^{-1}$ toward the southwest within IGS08 and $2 \mathrm{~mm} \mathrm{year}^{-1}$ toward the northeast within NAD83 (Wang et al., 2013). There are no stable sites that have velocities of $0 \mathrm{~mm}_{\text {year }}{ }^{-1}$ within the Houston metropolitan area with respect to the NAD83 and IGS08 reference frames.

The need for a consistent and stable reference frame has become critically important in the Houston metropolitan area because of the broad extent of subsidence and faulting activities since the 1980s. It is difficult to identify long-term stable benchmarks (reference sites) inside of the subsidence area. In order to integrate long-term GPS data collected by different agencies in different areas with different equipment into a uniform reference frame, a Stable Houston Reference Frame was established in 2012 (Wang et al., 2013). The local reference frame was realized by a 14-parameter simultaneous Helmert transformation from the global reference frame IGS08. This study updated the previous local reference frame by improving the geometrical configuration of reference stations and by including two additional years (2013 and 2014) of continuous data. All reference stations are located outside the Houston metropolitan area and they have a positional data set of 5 to 10 years. Figure 2 depicts the locations of 10 reference stations for the updated local reference frame, the stable Houston reference frame of 2014 (SHRF14). The positional coordinates of a site within the SHRF14 can be calculated through the following equations:

$$
\begin{aligned}
x(t)_{\mathrm{SHRF}} & =T_{x}(t)+[1+s(t)] \cdot x(t)_{\mathrm{IGS} 08} \\
& +R_{z}(t) \cdot y(t)_{\mathrm{IGS} 08}-R_{y}(t) \cdot z(t)_{\mathrm{IGS} 08} \\
y(t)_{\mathrm{SHRF}} & =T_{y}(t)-R_{z}(t) \cdot x(t)_{\mathrm{IGS} 08}+[1+s(t)] \cdot y(t)_{\mathrm{IGS} 08} \\
& +R_{x}(t) \cdot z(t)_{\mathrm{IGS} 08} \\
z(t)_{\mathrm{SHRF}} & =T_{z}(t)+R_{y}(t) \cdot x(t)_{\mathrm{IGS} 08}-R_{x}(t) \cdot y(t)_{\mathrm{IGS} 08} \\
& +[1+s(t)] \cdot z(t)_{\mathrm{IGS} 08}
\end{aligned}
$$

Here, $T_{x}(t), T_{y}(t), T_{z}(t), R_{x}(t), R_{y}(t), R_{z}(t)$, and $s(t)$ are the seven Helmert reference frame transformation parameters at epoch $t . T_{x}(t), T_{y}(t)$, and $T_{z}(t)$ are translations along $x, y$, and $z$ axes; $R_{x}(t), R_{y}(t)$, and $R_{z}(t)$ are counterclockwise rotations about these three axes; $s(t)$ is a differential scale change between IGS08 and SHRF. These seven parameters at a specific epoch $(t)$. They can be obtained from the following equations:

$$
\begin{aligned}
& T_{x}(t)=T_{x}\left(t_{0}\right)+T_{x}^{\prime} \cdot\left(t-t_{0}\right) \\
& T_{y}(t)=T_{y}\left(t_{0}\right)+T_{y}^{\prime} \cdot\left(t-t_{0}\right)
\end{aligned}
$$

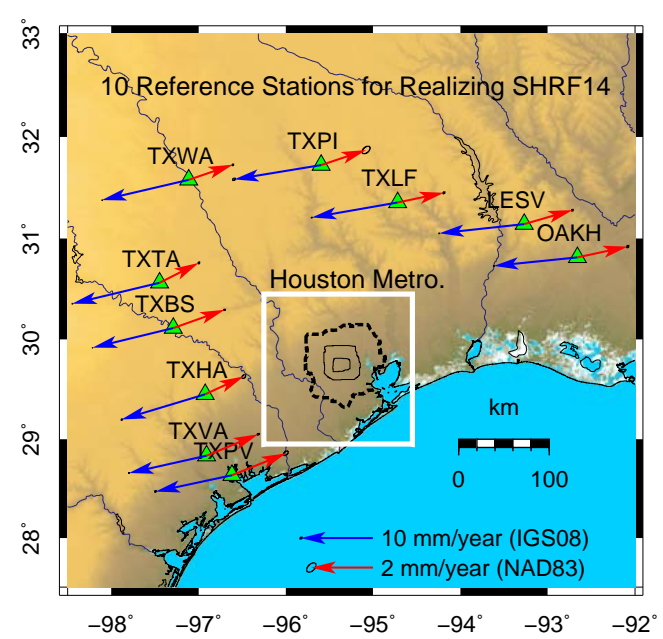

Figure 2. Map showing the locations of 10 reference stations used to realize the Stable Houston Reference Frame of 2014 (SHRF14). The vectors represent the horizontal velocity vectors with respect to IGS08(blue) and NAD83(red). The white box represents the Houston metropolitan area.

$$
\begin{aligned}
& T_{z}(t)=T_{z}\left(t_{0}\right)+T_{z}^{\prime} \cdot\left(t-t_{0}\right) \\
& R_{x}(t)=R_{x}\left(t_{0}\right)+R_{x}^{\prime} \cdot\left(t-t_{0}\right) \\
& R_{y}(t)=R_{y}\left(t_{0}\right)+R_{y}^{\prime} \cdot\left(t-t_{0}\right) \\
& R_{z}(t)=R_{z}\left(t_{0}\right)+R_{z}^{\prime} \cdot\left(t-t_{0}\right) \\
& s(t)=s\left(t_{0}\right)+s^{\prime} \cdot\left(t-t_{0}\right)
\end{aligned}
$$

Here, $t_{0}$ denotes a specific epoch that was used to align the two reference frames. It is set as 2013.0 in this study. $T_{x}\left(t_{0}\right)$, $T_{y}\left(t_{0}\right), T_{z}\left(t_{0}\right), R_{x}\left(t_{0}\right), R_{y}\left(t_{0}\right), R_{z}\left(t_{0}\right)$, and $s\left(t_{0}\right)$ are the seven Helmert-parameters at epoch $t_{0}$, which equal zeros since a site has the same coordinates at this epoch with respect the both reference frames. $T_{x}^{\prime}, T_{y}^{\prime}, T_{z}^{\prime}, R_{x}^{\prime}, R_{y}^{\prime}, R_{z}^{\prime}$, and $s^{\prime}$ are the first-time derivatives (rates) of these seven parameters, which are listed in Table 1.

\section{Current land subsidence}

Figure 3 depicts the land subsidence contours in the Houston metropolitan are for the time period from 2005 to 2014 . Continuous observations (>3 years) from 100 permanent GPS stations and 11 extensometer sites were used in calculating the contours. The color areas represent the groundwater regulation zones enforced by the local groundwater management agencies. The HGSD regulates the groundwater use in the Harris and Galveston Counties, which are divided into three regulation areas: Areas I, II, and III. The FBSD regulates groundwater use in Fort Bend County, which is divided into three areas: northern (Area A), southern (Area B), and the Richmond-Rosenberg subarea (Area RR). There is no considerable land subsidence in Brazoria County. The subsidence in the HGSD's Areas I and II has ceased 
Table 1. Fourteen Parameters for Helmert Reference Frame Transformation from IGS08 to SHRF14.

\begin{tabular}{llr}
\hline Parameter & Unit & IGS08 to SHRF14 \\
\hline & & $t_{0}=2013.0$ \\
$T_{x}\left(t_{0}\right)$ & $\mathrm{m}$ & 0.0 \\
$T_{y}\left(t_{0}\right)$ & $\mathrm{m}$ & 0.0 \\
$T_{z}\left(t_{0}\right)$ & $\mathrm{m}$ & 0.0 \\
$R_{x}\left(t_{0}\right)$ & radian & 0.0 \\
$R_{y}\left(t_{0}\right)$ & radian & 0.0 \\
$R_{z}\left(t_{0}\right)$ & radian & 0.0 \\
$s\left(t_{0}\right)$ & unitless & 0.0 \\
$\mathrm{~d} T_{x}$ & m year $^{-1}$ & $-1.490584 \mathrm{E}-02$ \\
$\mathrm{~d} T_{y}$ & m year $^{-1}$ & $-1.328112 \mathrm{E}-02$ \\
$\mathrm{~d} T_{z}$ & m year $^{-1}$ & $-2.326649 \mathrm{E}-02$ \\
$\mathrm{~d} R_{x}{ }^{*}$ & radian year $^{-1}$ & $4.177140 \mathrm{E}-09$ \\
$\mathrm{~d} R_{y}{ }^{*}$ & radian year $^{-1}$ & $-5.198959 \mathrm{E}-09$ \\
$\mathrm{~d} R_{z}{ }^{*}$ & radian year $^{-1}$ & $-1.699222 \mathrm{E}-09$ \\
$\mathrm{~d} s$ & 1 year $^{-1}$ & 0.0 \\
\hline
\end{tabular}

* Counterclockwise rotations of axes $(x, y, z)$ are positive.

$\left(<3 \mathrm{~mm} \mathrm{year}^{-1}\right)$ except for in a localized subsidence area located in the La Marque area (5-10 $\mathrm{mm}$ year $\left.{ }^{-1}\right)$. Groundwater pumping is strictly regulated in Areas I and II. Only $10 \%$ of the total water demand has been permitted to be withdrawn from groundwater in Area I and only $20 \%$ has been permitted to be withdrawn in Area II since 1999. Currently, two subsidence bowls have formed in The Woodlands-Spring area and the Katy area. The Woodlands-Spring subsidence bowl is located in both the northern portion of HGSD's Area III and the southern portion of LSGCD regulation area (the Montgomery County). Subsidence of up to $25 \mathrm{~mm}_{\text {year }}{ }^{-1}$ is occurring in the center of the subsidence bowl. There was no groundwater regulation in the HGSD's Area III until 2010. Current HGSD's regulation plan requires that no more than $20 \%$ of the total water demand can be withdrawn from the ground in Area III. Montgomery County is the fifth fastest growing county in Texas. Water for residents and businesses use was almost exclusively from groundwater before 2014 . Subsidence of up to $20 \mathrm{~mm} \mathrm{year}^{-1}$ is occurring within the subsidence bowl in the Katy area, which is located in the FBSD's Area A and southern Waller County. No groundwater regulation plans have been implemented in Waller County. The Katy area is growing rapidly, but it is not scheduled to utilize surface water resources in any of the existing groundwater reduction plans. Groundwater was the sole water source for residents and businesses as of 2014.

\section{Groundwater-level altitudes}

The Chicot and Evangeline aquifers are two major fresh water aquifers underlying the Houston metropolitan area and consequently the most of the subsidence has occurred as a direct result of groundwater withdrawal from these two

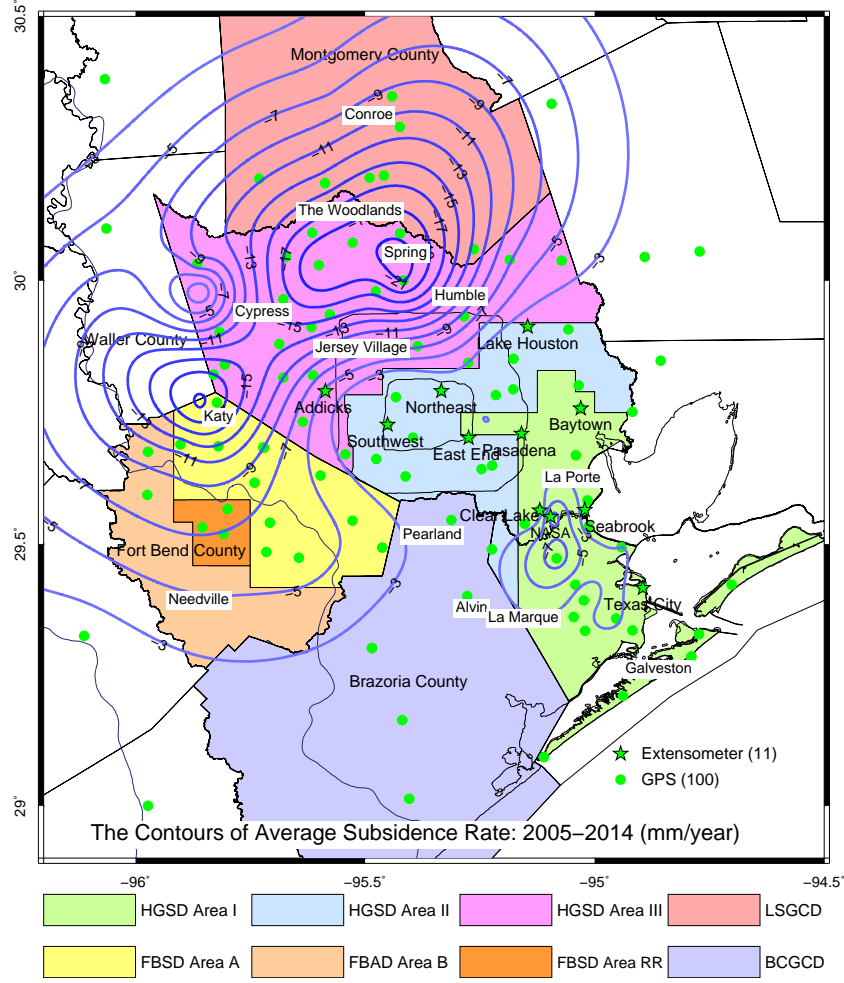

Figure 3. Average subsidence rate occurring from 2005 to 2014 in the Houston metropolitan area, Texas. The colored areas indicate the current groundwater conservation zones regulated by the Harris-Galveston Subsidence District (HGSD), the Fort Bend Subsidence District (FBSD), the Lone Star Groundwater Conservation District (LSGCD), and the Brazoria County Groundwater Conservation District (BCGCD).

aquifers (e.g., Coplin and Galloway, 1999; Kasmarek et al., 2014; Kearns et al., 2015). The two aquifers are hydraulically connected. Long-term groundwater-level changes that occur in one aquifer can affect the groundwater-level in the other one. As a result, the areas where water levels have declined or risen are approximately spatially coincident for the Chicot and the Evangeline aquifers. Figure 4 depicts the groundwater-level altitudes in the Chicot and Evangeline aquifers at the end of 2014 and the changes of groundwaterlevel altitudes during the past 10 years (2005-2014). Waterlevel measurements from 175 wells screened in the Chicot aquifer and 330 wells screened in the Evangeline aquifer were used to construct the contour maps. All groundwater data was obtained from the USGS National Water Information System (NWIS) (http://groundwaterwatch.usgs.gov).

Recent investigations indicate that the local preconsolidation heads of the groundwater within the Chicot and Evangeline aquifers in the Houston metropolitan area are approximately $35 \mathrm{~m}$ below the land surface $(-35 \mathrm{~m}$ ) (Kearns et al., 2015). The preconsolidation head is estimated as the approximate local groundwater level prior to excessive groundwater pumping that began in the 1940s. Figure 4 indicates that both 

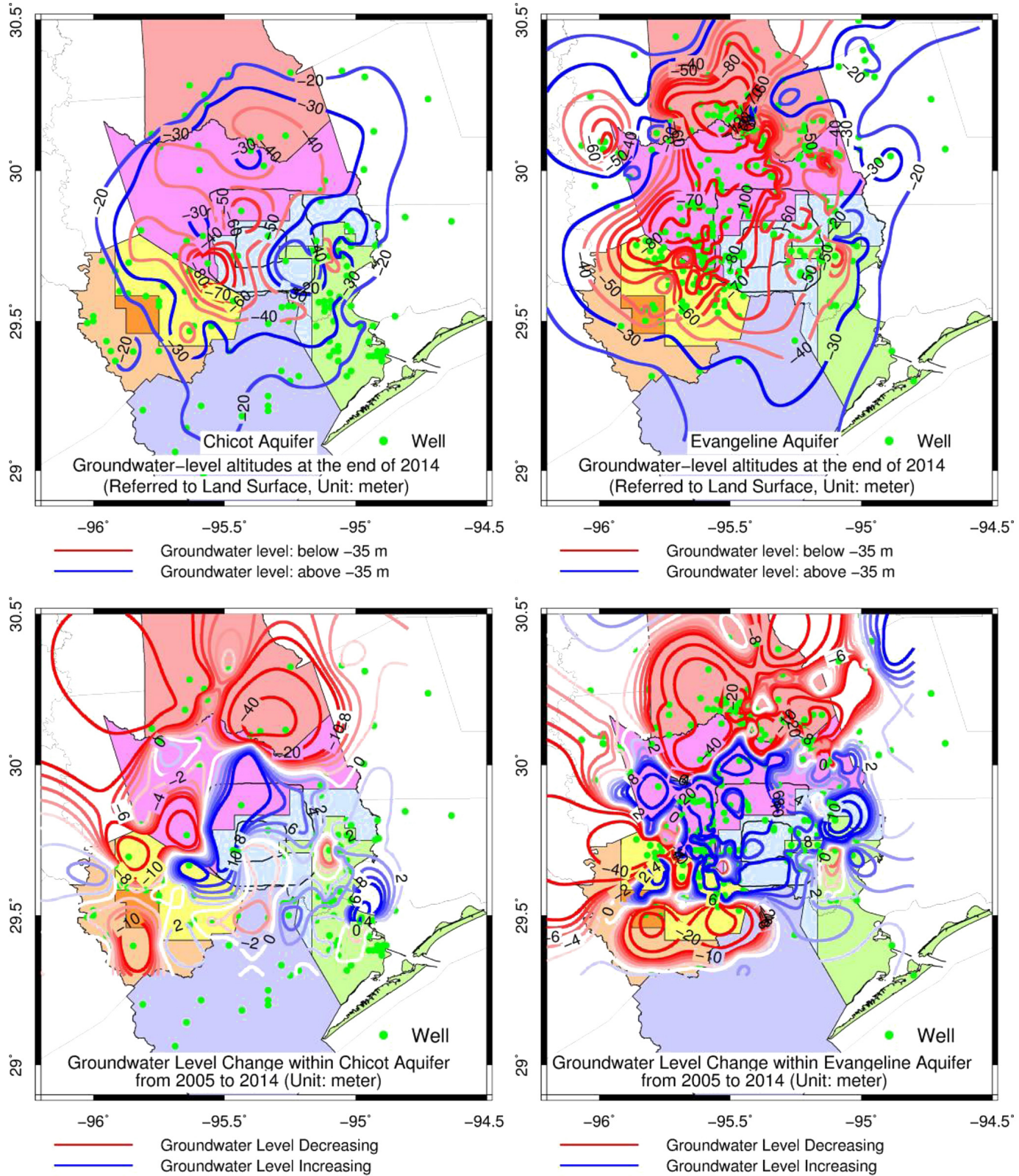

Figure 4. Contour maps showing groundwater-level altitudes within the Chicot and Evangeline aquifers at the end of 2014 and the changes of groundwater-level altitudes from 2005 to 2014. The colored areas represent the groundwater regulation zones as shown in Fig. 3.

the Chicot and Evangeline water-level altitudes are above the preconsolidation head $(-35 \mathrm{~m})$ in HGSD's Area I, the majority of FBSD's Area B, and in Brazoria County as of 2014. The Chicot groundwater-level altitudes are below the preconsolidation head in HGSD's Area III, the western HGSD's Area II, and southern Montgomery County. The Evangeline groundwater level is below the preconsolidation head within a much larger area. The deepest Evangeline groundwater level is approximately $100 \mathrm{~m}$ below the land surface in The Woodland-Spring area and the Katy area. The Evangeline and Chicot groundwater levels have been rising in HGSD's
Areas II and III during the past 10 years. The average groundwater level is rising at a rate of 1 to $3 \mathrm{~m} \mathrm{year}^{-1}$ in the Evangeline aquifer. The rising rate of the Chicot groundwater level is slower. The groundwater-level altitudes in the FBSD's Area $\mathrm{B}$ and Montgomery County declined at an approximate rate of 2 to $4 \mathrm{~m}_{\text {year }}{ }^{-1}$ over the past 10 years.

A comparison of current land subsidence, groundwater level altitudes, and their changes indicates a close correlation between groundwater-level altitude and aquifer compaction (subsidence). There is no considerable subsidence in the areas where the Chicot and Evangeline groundwater-level al- 
titudes are close to or above $-35 \mathrm{~m}$. In the areas where the groundwater-level altitudes are below $-35 \mathrm{~m}$ and the groundwater levels are still declining, the rate of subsidence is rapid (> $10 \mathrm{~mm}_{\text {year }}{ }^{-1}$ ). In the areas where the groundwater-level altitudes are below $-35 \mathrm{~m}$, but the groundwater levels are rising, the rate of subsidence is moderate $\left(<10 \mathrm{~mm} \mathrm{year}^{-1}\right)$. It appears that subsidence will continue to occur as long as the groundwater levels stay below about $-35 \mathrm{~m}$.

\section{Discussion and conclusions}

The Houston metropolitan area represents one of the largest subsidence areas in the USA (Galloway et al., 1999). The current dense GPS and groundwater monitoring networks in this area have provided direct measurements used for the purpose of studying the correlation between land subsidence and groundwater withdrawal and for the scientific management of groundwater and land resources. The groundwater regulations enforced by HGSD have successfully halted subsidence in areas that were once heavily subsiding (HGSD'S Area I and II) and have slowed the rate of subsidence in recently developed suburban area (HGSD's Area III). Groundwater levels have been stabilized in HGSD's Area I (above $-35 \mathrm{~m}$ ) and have been rising in HGSD's Area II and the majority of Area III. Based on the success if the subsidence districts in mitigating the occurrence, it is evident that groundwater resources and subsidence are manageable.

Accurate monitoring of subsidence over long period of time and of large area is vital to provide calibration data for subsidence modeling, prediction, and management purposes. A precise local geodetic infrastructure can be defined with three fundamental components: a dense GPS network, a stable local reference frame, and sophisticated software packages for data processing. This article updated the local reference frame with an improved geometrical configuration of reference stations and two additional years of data. SHRF14 provides a consistent and accurate reference frame for studying local ground deformations over space and time and serves the broad research and surveying communities. The local reference frame will be incrementally improved and synchronized with the updates of the IGS reference frame.

This study demonstrated an approach of using publicly available GPS data to conduct millimeter-accuracy land subsidence studies in an urban environment. Numerous CORS networks have been installed in urban areas all over the world during the past two decades for the purpose of conducting accurate land surveying and for scientific applications. It is hoped that this study will promote the applications of GNSS techniques in subsidence monitoring and contribute to the reduction of subsidence hazards in other subsidence-prone areas.
Acknowledgements. This study was supported by an NSF CAREER award EAR-1229278 and an NSF MRI award EAR1242383. The authors acknowledge USGS and HGSD for providing groundwater, extensometer, and GPS data to the public.

\section{References}

American Association of Petroleum Geologists: Salt tectonism of the US gulf coast basin (CD-ROM), Geographic Information System-Upstream Digital Reference Information Library (GIS-UDRIL), available at: http://www.datapages.com/ associated-websites/documents/gisudrilbrochurejan2013 (last access: 5 October 2015), 2011.

Bertiger, W., Desai, S., Haines, B., Harvey, N., Moore, A., Owen S., and Weiss, J.: Single receiver phase ambiguity resolution with GPS data, J. Geod., 84, 327-337, 2010.

Blewitt, G.: Overview of the SNARF Working Group, its activities, and accomplishments, Report of the Ninth SNARF Workshop, available at: https://www.unavco.org/projects/past-projects/ snarf/snarf.html (last access: 5 October 2015), 2008.

Blewitt, G., Kreemer, C., Hammond, W. C., and Goldfarb, J. M.: Terrestrial reference frame NA12 for crustal deformation studies in North America, J. Geodyn., 72, 11-24, 2013.

Coplin, L. and Galloway, D.: Land subsidence in the United States. Houston Galveston, Texas: managing coastal subsidence, in: Galloway, edited by: D., Jones, D. R., and Ingebritsen, S. E., Land subsidence in the United States: US Geological Survey Circular 1182, 35-48, 1999.

Galloway, D., Jones, D., and Ingebritsen, S.: Land subsidence in the United States, USGS Circular 1182, US Geological Survey, Reston, VA, 35-48, 1999.

Kasmarek, M., Gabrysch, R., and Johnson, M.: Estimated landsurface subsidence in Harris County, Texas, 1915-1917 to 2001, USGS Sci. Invest. Map 3097, 2 sheets, US Geological Survey, Reston, available at: http://pubs.usgs.gov/sim/3097/ (last access: 5 October 2015), 2009.

Kasmarek, M., Johnson, M., and Ramage, J.: Water-level altitudes 2013 and water-level changes in the Chicot, Evangeline, and Jasper aquifers and compaction 1973-2012 in the Chicot and Evangeline aquifers, Houston-Galveston region, Texas, USGS Sci. Invest. Map 3263, US Geological Survey, Reston, VA, 130, 2014.

Kearns, T. J., Wang, G., Bao, Y., Jiang, J., and Lee, D.: Current Land Subsidence and Groundwater Level Changes in the Houston Metropolitan Area, Texas (2005-2012), J. Surv. Eng., 05015002, 1-16, 2015.

Pearson, P. and Snay, R.: Introducing HTDP 3.1 to transform coordinates across time and spatial reference frames, GPS Solut., 17, $1-17,2013$.

Shah, S. D. and Lanning-Rush, J.: Principal faults in the Houston, Texas, Metropolitan Area, USGS, Scientific Investigations Map 2874, available at: http://pubs.usgs.gov/sim/2005/2874/ (last access: 5 October 2015), 2005.

Snay, R. A. and Soler, T.: Modern Terrestrial Reference Systems. Part 2: The evolution of the NAD 83, Professional Surveyor, 20, 16-18, 2000.

Soler, T. and Snay, R. A.: Transforming positions and velocities between the International Terrestrial Reference Frame of 2000 and North American Datum of 1983, J. Surv. Eng., 130, 49-55, 2004. 
Wang, G.: Millimeter-accuracy GPS landslide monitoring using precise point positioning with single receiver phase ambiguity resolution: a case study in Puerto Rico, J. Geod. Sci., 3, 22-31, 2013.

Wang, G. and Soler, T.: Using OPUS for measuring vertical displacements in Houston, TX, J. Surv. Eng., 139, 126-134, 2013.

Wang, G. and Soler, T.: Measuring Land Subsidence Using GPS: Ellipsoid Height vs. Orthometric Height, J. Surv. Eng., 141, 112, 2014.

Wang, G., Yu, J., Ortega, J., Saenz, G., Burrough, T., and Neill, R.: A stable reference frame for ground deformation study in the Houston metropolitan area, Texas, J. Geod. Sci., 3, 188-202, 2013.

Wang, G., Yu, J., Kearns, T. J., and Ortega, J.: Assessing the accuracy of long-term subsidence derived from borehole extensometer data using GPS observations: case study in Houston, Texas, J. Surv. Eng., 140, 1-7, 2014.
Yu, J., Wang, G., Kearns, T. J., and Yang, L.: Is there deep-seated subsidence in the Houston-Galveston area?, Int. J. Geophys., 2014, 942834, 1-11, doi:10.1155/2014/942834, 2014.

Zilkoski, D. B., Hall, L., Mitchell, G., Kammula, V., Singh, A., Chrismer, W., and Neighbors, R.: The Harris-Galveston coastal subsidence district/national geodetic survey automated global positioning system subsidence monitoring project, Proc., US Geological Survey Subsidence Interest Group Conf., Galveston, Texas, 27-29 November 2001, USGS OpenFile Report, 03-308, 13-28, 2003. 